The basis for the mucosal immune response to gluten seems likely to be the precipitation of antigen-antibody complexes in the small intestinal mucosa with complement activation. ${ }^{6}$ IgG, IgM, and complement may all be implicated in the persisting, long-term damage. Some interesting work on skin testing for diagnostic screening, from Oxford ${ }^{7}$ and Bristol, ${ }^{8}$ suggested that in time we may be able to reduce the numbers of intestinal biopsies needed for diagnosis-one of the aims of the Coeliac Society, which sponsored the Oxford work.

We still have to agree on how abnormal the untreated mucosa should be to qualify for the diagnosis of coeliac disease, how much improvement should result from gluten withdrawal, and how much damage should follow gluten challenge. Finally, what about the "unresponsive coeliac"? A lack of response is uncommon so long as a patient continues his gluten-free diet strictly, but there are increasing reports of adult patients who have responded clinically and morphologically to gluten withdrawal and who then, after a lapse from the diet, have become unresponsive to an apparently strict regimen. ${ }^{9}$ Some of these patients can be tided over an unresponsive period, but this complication of coeliac disease merits more study.

1 Walker-Smith, J A, Archives of Disease in Childhood, 1970, 45, 523

2 Walker-Smith, J A, Archives of Disease in Childhood, 1972, 47, 155

${ }^{3}$ Falchuk, Z M, Rogentine, G M, and Strober, W, fournal of Clinical Investigation, 1972, 51, 1602.

- Keuning, J J, et al, Lancet, 1976, 1, 506.

5 Mann, D L, et al, Lancet, 1976, 1, 110

${ }^{6}$ Doe, W F, Henry, K, and Booth, C C, in Proceedings of the Second International Coeliac Symposium, eds W Th J M Hekkens and A S Pena, p 189. Leiden, Stenfert Kroese, 1974.

7 Anand, B S, Truelove, S C, and Offord, R E, Lancet, 1977, 1, 118.

${ }^{8}$ Baker, P G, and Read, A E, Quarterly fournal of Medicine, 1976, 45, 603.

o Neale, G, British Medical fournal, 1968, 2, 678.

\section{Small-bowel ischaemia and the contraceptive pill}

Among the many cardiovascular complications of the contraceptive pill one of the least familiar is small-bowel ischaemia -but one associated with a high mortality rate and much morbidity. Hoyle et $a l^{1}$ have recently reviewed 21 cases and found that half the patients had died and half had required two or more operations, resulting in the removal of much of the small bowel.

Small-bowel ischaemia occurs in women taking the pill as a result of either mesenteric artery or mesenteric vein thrombosis. Arterial thrombosis carries nearly twice the mortality of venous thrombosis but is only half as common. The dosage of oestrogen seems to be an important factor: nine of the women reviewed by Hoyle $e t \mathrm{al}^{1}$ had been taking $0.5 \mathrm{mg}$ daily, while the remaining 12 women had been taking a higher dose. Over half the women had been taking an oral contraceptive for a year or more, but two were only in their first cycle. In Hoyle's personal series of three patients all were of blood group A rhesus positive-a group already shown to predispose to thrombosis..$^{2-4}$ All three were smokers and two were hypertensive. Again, the association of hypertension and blood group A has been reported in this condition. ${ }^{5}$

Ischaemic colitis, but transient, has also been reported in young women taking oral contraceptives. ${ }^{6-8}$ In these cases the patients had no predisposing disorders and presented with the classical symptoms of abdominal pain and bloody diarrhoea. Diagnosis was based on the clinical picture and the appearances on barium enema-a narrowed segment of colon and thumb-printing of the mucosa. In these patients stopping the use of oral contraceptives allowed the bowel to recover, and later barium enema examinations showed normal results.

In contrast, the symptoms of small-bowel ischaemia are both more varied and vague, and the diagnosis is often delayed. The dominant presenting symptom in small-bowel ischaemia, found in all patients, is abdominal pain. In over one-quarter of the reported cases the pain had been present for two or more weeks, suggesting a slow onset. Some patients had associated nausea and vomiting, while others complained of diarrhoea. Occasional patients have had a haematemesis or melaena, depending on the level of the ischaemic segment. On examination the patient has usually been found to be febrile with generalised abdominal tenderness. Bowel sounds are present unless infarction has occurred, in which case there is rebound tenderness. Haematological investigations may show a raised white count and increased serum fibrinogen and fibrinogen degradation products. On barium meal and follow through there may be a narrowed segment of small bowel. ${ }^{9}$ The place of ${ }^{131} \mathrm{I}$ uptake and angiography in the diagnosis of this condition has yet to be established.

Unfortunately, in nearly all the cases reported the diagnosis has been made only at laparotomy, when the bowel was usually infarcted. The fact that many of the patients had had pain for two or more weeks suggests that the condition might well be reversible if it could be detected earlier. A diagnosis of smallbowel ischaemia should be carefully considered in any woman taking an oral contraceptive who presents with vague abdominal pain and has an associated condition known to predispose to circulatory disorders: cigarette smoking, hyperlipidaemia, diabetes, hypertension, obesity, ${ }^{10}$ or blood group A. If small-bowel ischaemia seems the likely diagnosis the contraceptive pill should be stopped immediately and treatment started with heparin. In this way the mesenteric thrombosis might be arrested before ischaemia becomes irreversible.

1 Hoyle, M, et al, British fournal of Surgery, 1977, 64, 533.

2 Jick, R, et al, Lancet, 1977, 1, 539.

3 Fagerhol, M K, Abildgaard, V, and Kornstad, L, Lancet, 197.1, 2, 664

4 Mourant, A E, Kopec, A C, and Domaniewsha-Sobczak, S K, Lancet, $1971,1,223$.

${ }^{5}$ Lowry, J B, Orr, K G, and Wade, W G, Fournal of the Irish Medical Association, 1969, 62, 260.

- Kilpatrick, Z M, et al, New England fournal of Medicine, 1968, 278, 438

7 Hurwitz, R L, et al, Annals of Surgery, 1970, 172, 892.

${ }^{8}$ Cotton, P B; and Thomas, M L, British Medical fournal, 1971, 3, 27.

${ }^{9}$ Nothmann, B J, Chittinand, S, and Schuster, M M, American fournal of Digestive Diseases, 1973, 18, 361.

10 Mann, J I, et al, British Medical fournal, 1975, 2, 241.

\section{Flap lacerations}

Any experienced casualty surgeon knows that the combination of a V shaped wound on the shin and an elderly woman usually indicates trouble ahead. It is likely to take a long time to heal, and the outlook will be worse if the flap is hinged at its distal edge. Why should these lesions be so troublesome? The primary factors are the thin skin, loss of tissue vitality, dependent position, and slower healing time in the leg, while a distally based flap further exaggerates the difficulties of blood supply and venous drainage. The final insult may be 